\title{
The Corrosion Erosion of Ship Propeller Al 7075 Produced by Gravity Sand Casting
}

\author{
Milka Rante $^{\mathrm{a}, \mathrm{b}, *}$, Muhammad Syahid ${ }^{\mathrm{c}}$, Onny Sutresman ${ }^{\mathrm{d}}$ \\ aDepartment of Mechanical Engineering, Engineering Faculty, Universitas Kristen Indonesia Toraja. Email: milka_rante@yahoo.com \\ ${ }^{b}$ Foundry Laboratory, Mechanical Engineering, Engineering Faculty, Universitas Hasanuddin. \\ ${ }^{c}$ Foundry Laboratory, Mechanical Engineering, Engineering Faculty, Universitas Hasanuddin. \\ ${ }^{\mathrm{d}}$ Foundry Laboratory, Mechanical Engineering, Engineering Faculty, Universitas Hasanuddin.
}

\begin{abstract}
Propeller is one of the important components of ships and boats that function as motor or boat propulsion. The mechanical properties required in propeller material are high toughness, easy to cast, and good engine capability, as well as good resistance to corrosion and erosion. One of the aluminum alloys that have been widely used in major vessels in propeller systems is the Nickel-aluminum-bronze (NAB) alloy because it has an excellent combination of mechanical properties and corrosion-erosion resistance. Another type of aluminum alloy that is widely used as a machining component is the Al 7075 T651 because it has the highest strength among other aluminum alloys. The mechanical properties of the Al $7075 \mathrm{~T} 651$ are directly proportional to the erosion resistance of the propeller which agrees with the pot tester porridge. The higher the value of the erosion propeller failure that occurs also increases with increasing testing rotational speed. For corrosion, a propeller with air testing media at a speed of $1000 \mathrm{rpm}$ which results in significant corrosion products.
\end{abstract}

Keywords: Al 7075 T651; corrosion erosion; slurry pot tester

\section{Introduction}

Propeller is one of the important components of ships and boats that function as a motorboat or boat propulsion. For vehicles operating at sea, the main criteria for material selection depend on strength, stiffness, heavy thermal expansion and corrosion resistance to seawater. The material used to make a propeller depends on the strength, ease of manufacture, production methods, environment, weight, and others. Also, the material used for the propellers must be lightweight, strong and resilient, easily installed and resistant to erosion and corrosion.

Materials that are widely used as propeller materials are brass (brass) or aluminum alloy (aluminum alloy), both of these materials are widely used because they are easily cast and relatively resistant to corrosion [1]. One of the aluminum alloys that are widely used in ships, especially in propeller systems, is the Nickel-aluminum-bronze (NAB) alloy because it has an excellent combination of mechanical properties and corrosion-erosion resistance [2]. Another aluminum alloy that is starting to be used is Al 7075. Al 7075 is an aluminum alloy with $\mathrm{Al}-\mathrm{Zn}-\mathrm{Mg}-\mathrm{Cu}$ as its main element [3] because it has good mechanical properties such as high

\footnotetext{
${ }^{*}$ Corresponding author. Tel: +62 813-4226-6124

Jl. Nusantara No.12 Makale, Kabupaten Tana Toraja 91811
}

strength comparable to steel [4]. Comprehensively, Al 7075 has interesting properties such as high strength, toughness, ductility and good fatigue resistance [5].

As a driving component of the ship, the ship's propeller rotates at high speed and experiences corrosion erosion due to the accumulation of rotational speed and particles present in the water which ultimately results in cavitation Corrosion is a phenomenon of material quality degradation or material degradation [6] that will not stop. Corrosion is caused by the influence of the surrounding environment. In addition to chemical reactions, the corrosion process by electrochemical processes involves the transfer of electrons from the reduction of metal ions and the deposition of metals from the surrounding environment (air, acid, dew, seawater, lake water, and river water) [7].

In his research [8] said that in addition to the influence of turbulence of flow, salinity in seawater has a very big influence on the rate of corrosion of the propeller. The greater the salinity the greater the rate of corrosion that occurs. In addition to salinity, the rotation speed is also very influential on the corrosion rate. The greater the rotational speed the greater the corrosion rate. This is influenced by solids dissolved in seawater that experience friction with the sample surface so that it can erode the surface of the sample. 
Another thing that also affects the rate of corrosion is the temperature of seawater.

It can be concluded that Al 7075 alloy has good mechanical strength to be applied as a propeller material. Although not yet known how its resistance to erosioncorrosion. Davis [9] in his book states that giving a slightly higher temper treatment can provide a better combination of strength, corrosion resistance, and fracture resistance. In this study, the aluminum alloy used was Al 7075 T651 in Table 1.

\section{Research Materials and Methods}

The material used in this study is aluminum Al 7075 T651 in the form of plates. The test specimen was made in the form of a propeller with 3 leaves with detailed dimensions as shown in Fig. 1(a). Propeller is made by casting using sand molds according to the design shown in Fig. 1(b). Leaking using the upper channel or direct channel, as shown in Fig. 1(c). The propeller that has been cast finished using sandpaper with the same grade to remove uneven parts on the surface of the propeller.
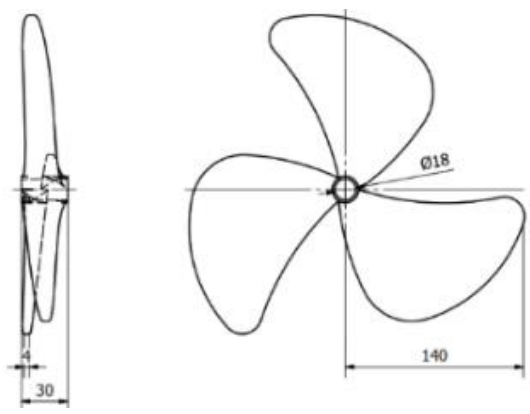

(a)
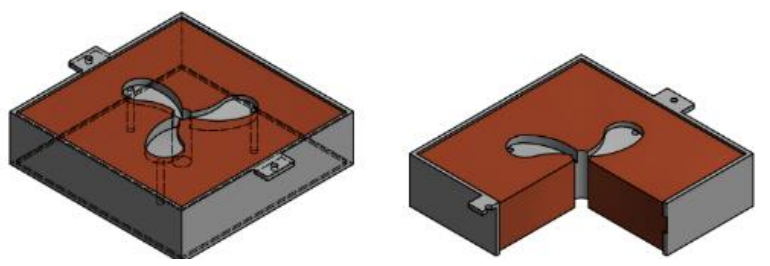

(b)

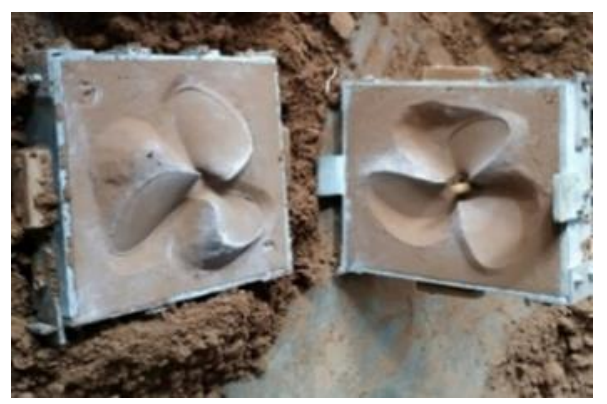

(c)

Figure 1. (a) Design propeller, (b) Sand mold design, (c) Ready-made sand mold
Table 1. Composition of Al 7075 plate

\begin{tabular}{ccccccc}
\hline $\mathrm{Al} \%$ & $\mathrm{Zn} \%$ & $\mathrm{Mg} \%$ & $\mathrm{Cu} \%$ & $\mathrm{Cr} \%$ & $\mathrm{Fe} \%$ & $\mathrm{Si} \%$ \\
\hline 89.72 & 5.57 & 2.39 & 1.67 & 0.28 & 0.25 & 0.13 \\
\hline
\end{tabular}

After the propeller is finished, initial characterization is done by weighing and mechanical testing using Portable Hardness Test. Hardness testing is carried out on the Tip and Propeller Hub sections. After initial mechanical testing and weighing, erosion-corrosion testing is then carried out. Erosion corrosion testing is done by using the pot tester method. Fig. 2(a) is a design pot tester. Pot tester container is made of 280 litre plastic containers. The mechanical system uses 2 types of electric motors so that 2 variations of rotational speed, 1000 and $700 \mathrm{rpm}$ are obtained in each container. The transmission system uses a pulley that is connected to 2 shafts with a tilt of 150 where the propeller will be installed. Propeller position as shown in Fig. 2(b). To the test water, $3 \%$ of silica sand is added from the total volume of the test water. The size of the silica sand used is $354 \mu \mathrm{m}$. Tests using seawater and river water with a 16-hour long test for each propeller.

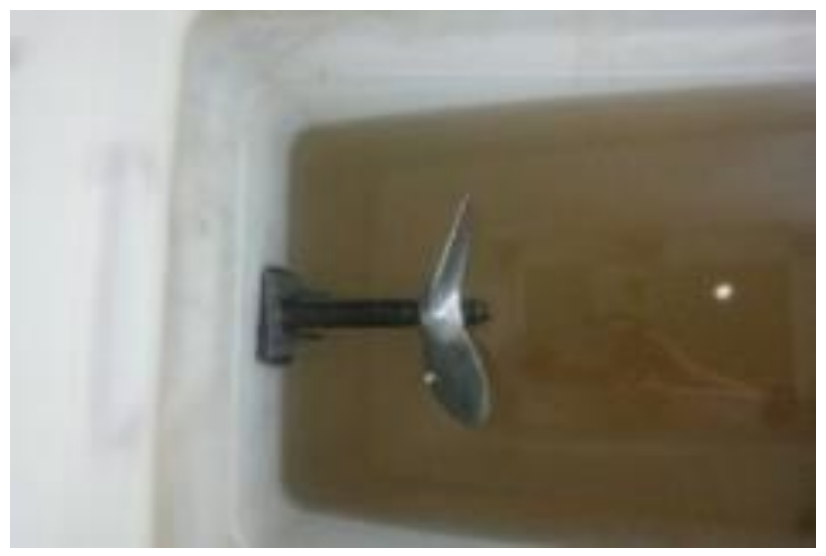

(a)

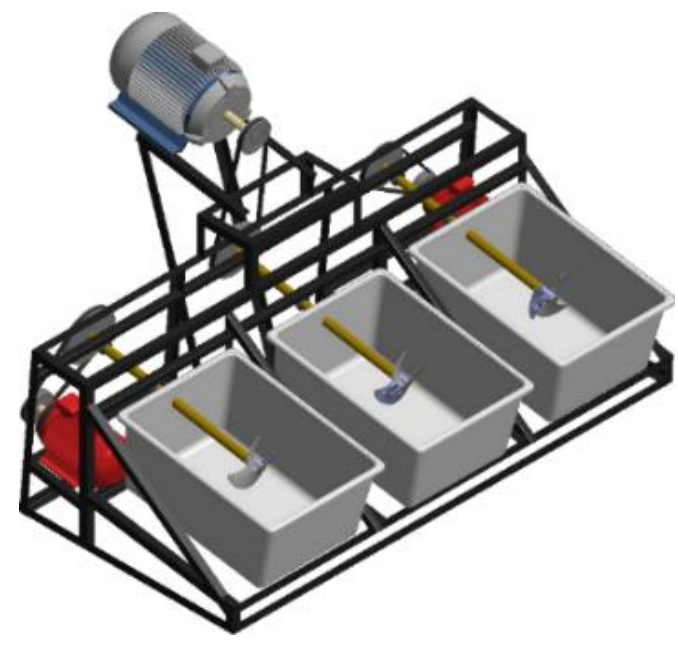

(b)

Figure 2. (a) Design pot tester, (b) Propeller position in pot tester 


\section{Data Analysis and Discussion}

\subsection{Foundry propeller}

The casting propeller as shown in Fig. 3 is then observed for its microstructure. From the microstructure observation shown in Figs. 4(a) and (b), there is no visible porosity in the casting product. The $\alpha-\mathrm{Al}$ phase appears as the main phase with a little $\mathrm{MgZn} 2$ on the grain line. The size of the grains on the hub and left propeller tend to have the same size and density.

\subsection{Hardness test}

The hardness test results in Fig. 5 show the hardness value at the hub is higher with a hardness value of $270.8 \mathrm{HL}$, while the tip part of the hardness value is $255.8 \mathrm{HL}$. This hardness value is related to the results of the microstructure where the results of the microstructure observation show that the grain size of the tip part of Fig. 4(a) and hub in Fig. 4(b) of propeller has a size that is not much different. It also appears that the tip of the grain spacing is denser than the grain spacing of the tip.

\subsection{Weight Loss}

Measurement of weight loss is done before and after testing with a pot tester. Figure 6 shows a graph of the percentage of propeller weight loss that has been tested with a pot tester in seawater testing media. In general, the greater the weight loss with increasing the rotational speed of the pot tester. The greatest weight loss occurs at a speed of 1000 rpm with seawater testing media with 0.28 grams of weight loss. Likewise, propellers tested with river water media lost the greatest weight at a rotational speed of $1000 \mathrm{rpm}$ with 0.13 grams of weight loss.

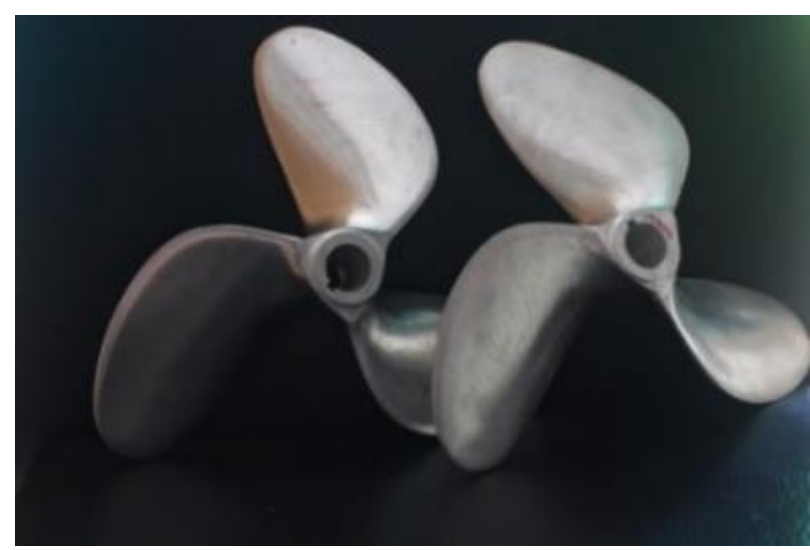

Figure 3. Foundry propeller

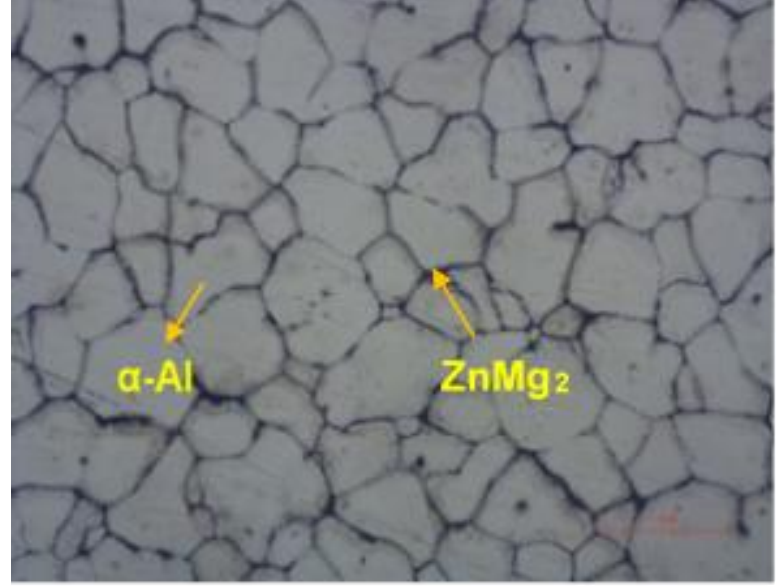

(a)

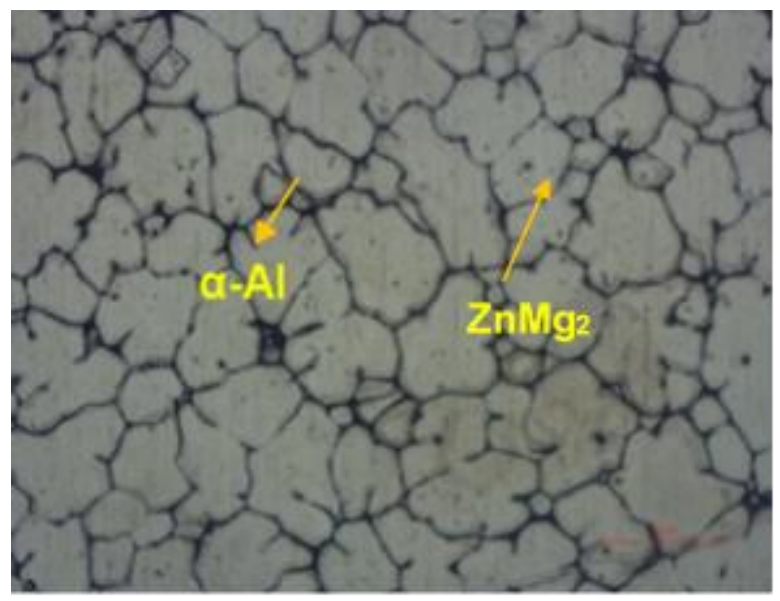

(b)

Figure 4. Casting tip propeller micro structure (a) Hub, (b) Tip

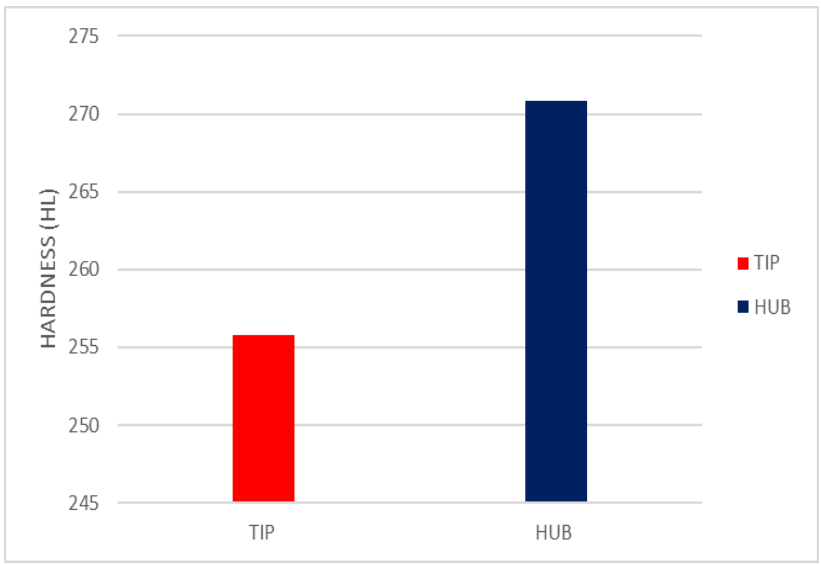

Figure 5. Hardness tip and hub propeller values 


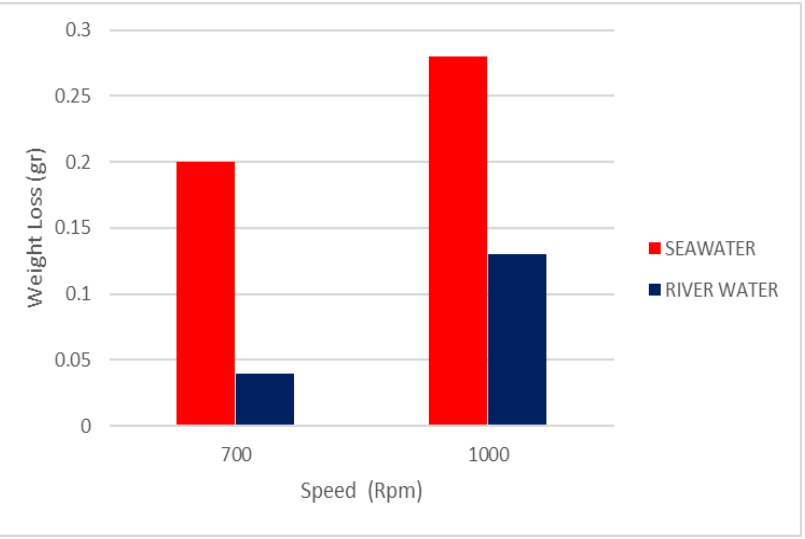

Figure 6. Graph of the effect of speed on propeller weight loss

The greatest weight loss at a speed of $1000 \mathrm{rpm}$ is an indication of erosion-corrosion which is the accumulation of velocity of fluids and solid particles that damage the metal surface and the protective film layer. The erosion-corrosion mechanism starts with the attack of air bubbles that attach to the surface of the metal protective layer because the turbulent flow that passes through the metal surface then the air bubbles erode and damage the protective layer which will further accelerate the corrosion rate.

Table 2. Macro photo tip propeller

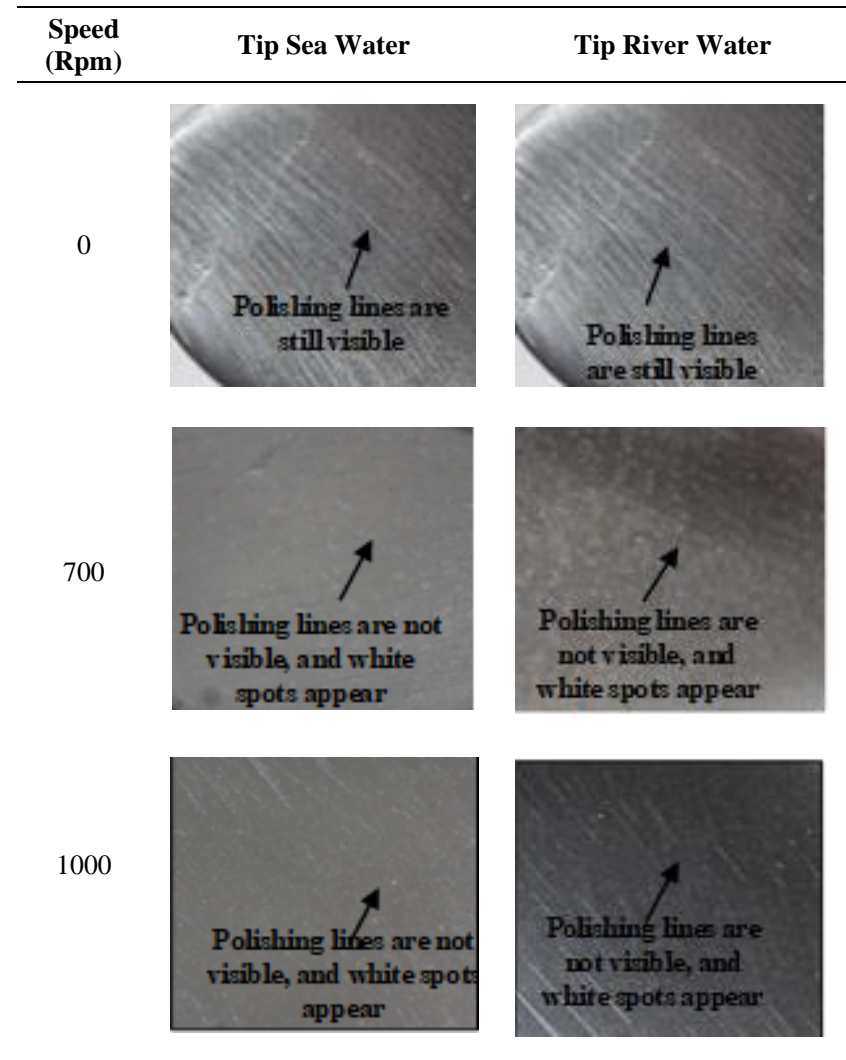

Table 3. Macro photo hub propeller

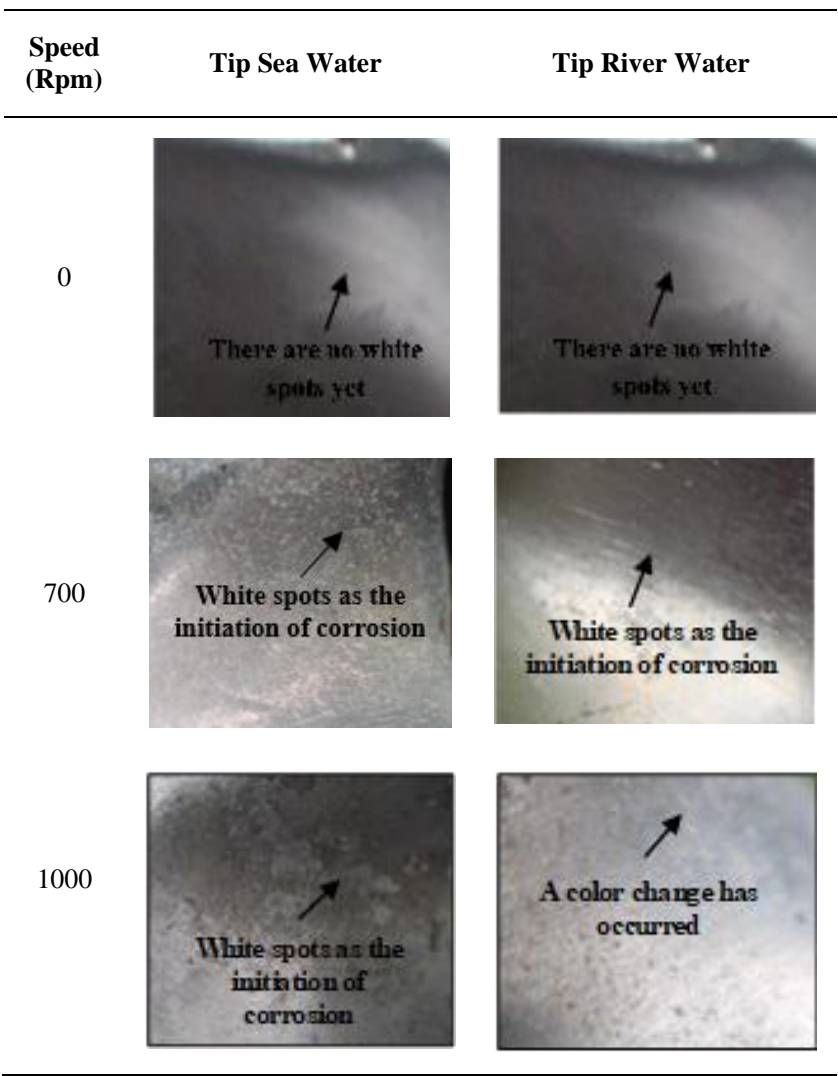

Table 4. Microscope optic tip propeller

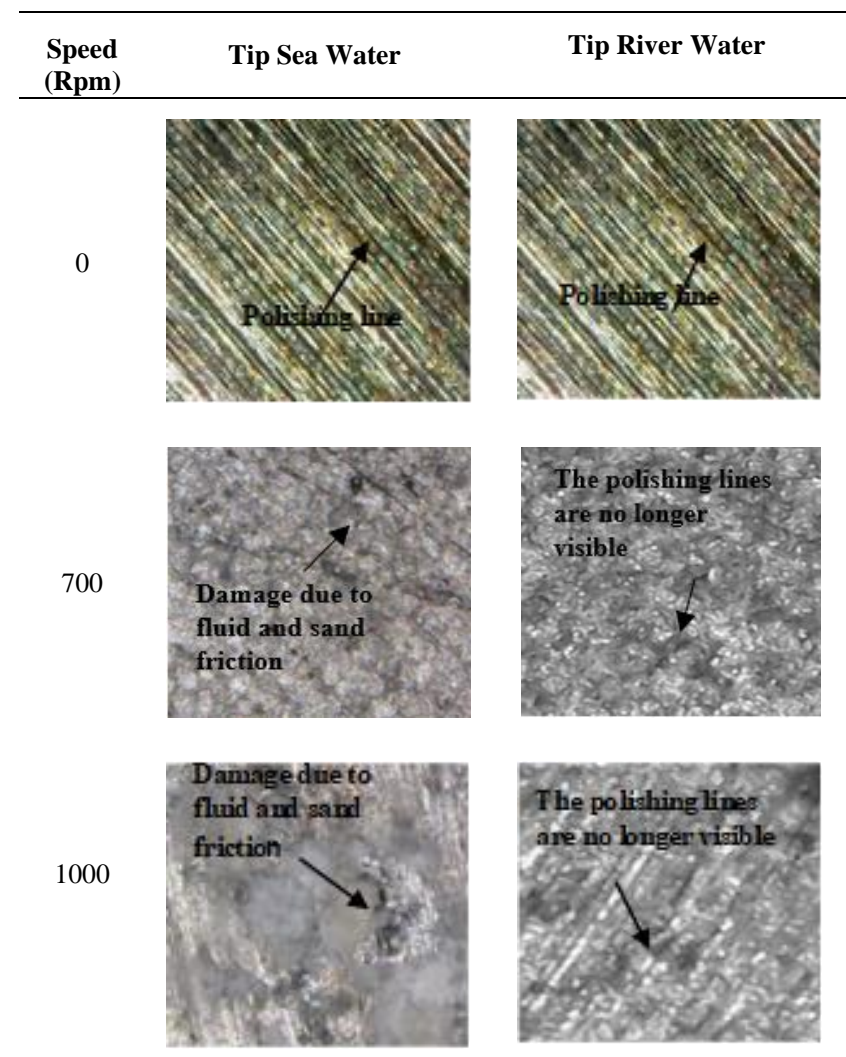


Table 5. Microscope optic hub propeller

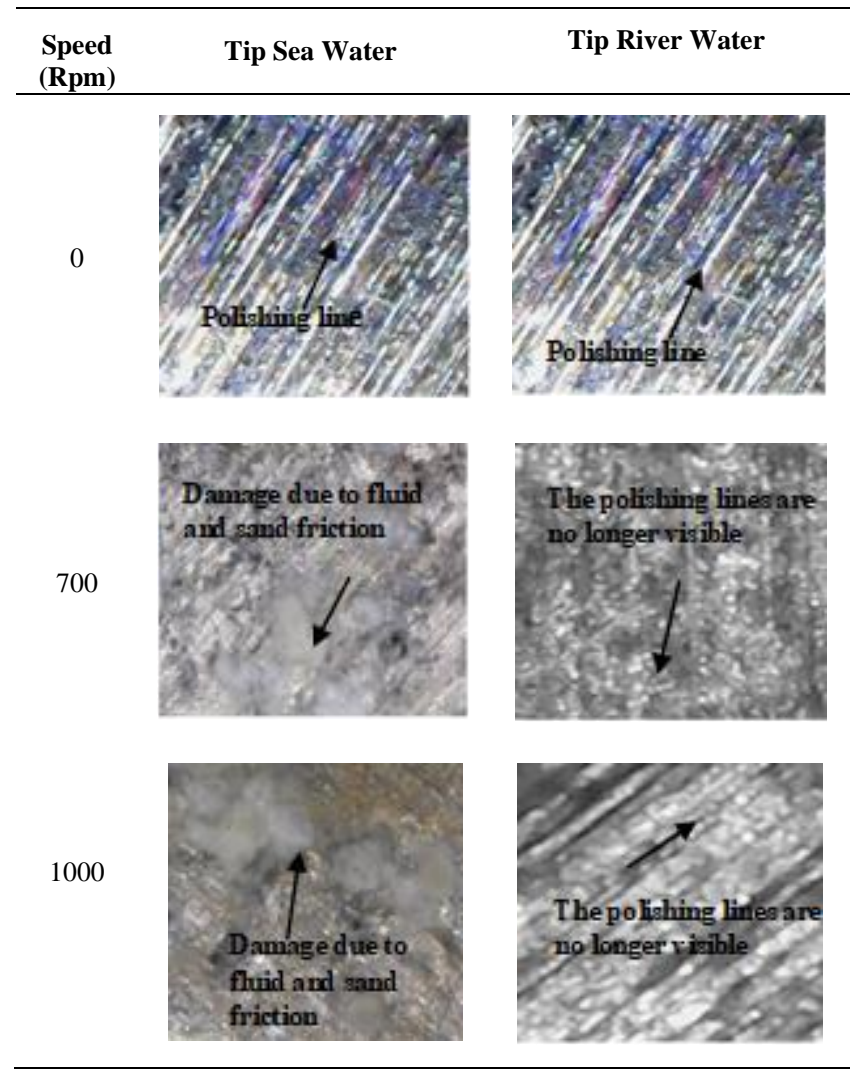

\subsection{Segmentation design}

From the results of the surface roughness test, it can be seen the difference in the surface of the propeller before and after the test which is also compared with the weight reduction of the propeller. The surface roughness value has decreased significantly after testing, especially at the tip of the propeller. In this study, the roughness value has decreased rather than increased due to the friction of the fluid and the particles in the water working like sandpaper on the surface of the propeller so that the surface of the propeller becomes smoother.

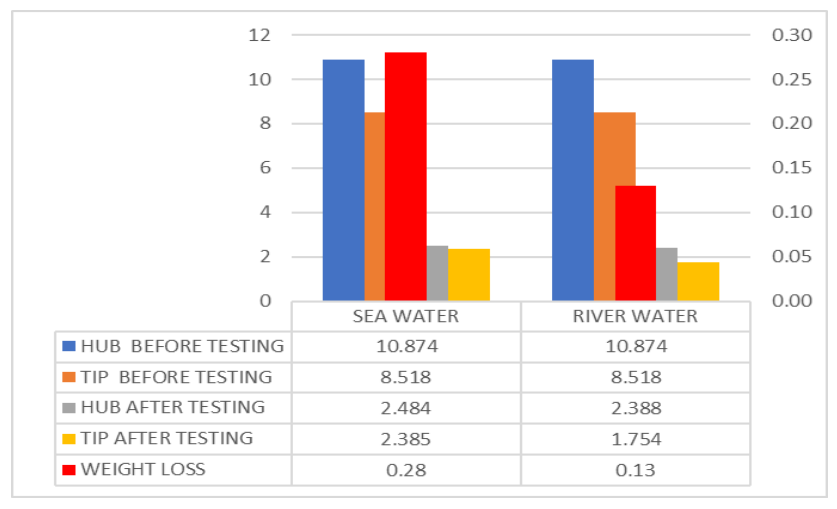

Figure 7. The relationship between surface roughness and propeller weight loss
The comparison is shown in Fig. 7. The greater the decrease in surface roughness value, the greater the decrease in the weight of the propeller. Changes in the surface roughness of the blades can be seen in macro photography and optical microscopy which were carried out before and after testing with a pot tester.

\subsection{Macro Photo and Microscope Optic}

With macro photos, it can be seen visual differences on the surface of the propeller. The surface of the propeller tested in seawater corrosion products is seen more clearly, both on the tip and the hub. At $1000 \mathrm{rpm}$, white spots that are indicated as corrosion initiation are followed by significant color changes from bright colors to dull colors. White spots and color changes appear more on the propeller hub of Table 3 when compared to the tip of in Table 4, colors change and fewer white spots. Turbulence flow has a significant impact because where in turbulent flow, air bubbles will be more pressurized so that attacks in the form of collisions and friction become stronger attacking metal surfaces due to mechanical wear that causes corrosion.

Another thing that affects is surface roughness. Huda and Aristianto [10] said that rough surfaces are the most susceptible to corrosion because on these surfaces bubbles form faster. These bubbles themselves are the effect of reducing the hydrodynamic pressure in certain parts as a fluid effect that attacks the surface of the propeller. From surface roughness testing, the hub of the propeller is rougher than the end of the propeller. At the end of Table 5 the difference in the surface of the propeller before and after being tested. The blades that have not been tested are still clearly visible traces of polishing lines from sandpaper that can be seen clearly on an optical microscope in Table 5 and Fig. 7. The higher the round polishing line the more invisible. This also shows that erosion has occurred on the surface of the blades due to fluid and sand friction.

In addition to macro photos, optical microscopy was also carried out to see more clearly the erosion-corrosion that occurs in the propeller. The optical microscope results in Table 5 and Fig. 7 show the erosion and corrosion that occurs on the surface of the propeller. This is indicated by the holes that occur on the surface of the propeller. The propeller with seawater testing media suffered the most damage compared to the propeller tested with river water media. In the Hub and tip propeller tested with seawater media, the hole is seen caused by friction from the fluid and sand. The formed hole is then filled with silica sand. As for the hub section, it was tested with river water testing media, no holes were seen as a result of fluid and sand friction. The most severe damage occurred in the propellers tested at $1000 \mathrm{rpm}$ on the hub and tip. Damage to the propeller with Al 7075 T651 material is identified as hole corrosion, crevice corrosion, and peeling.

This is by Sasono et al. [11] which states that Al 7075 T6 tends to be susceptible to local corrosion, such as pitting, intergranular corrosion, or peeling skin. In the results of the study in [12], the corrosion that occurred on Al 7075 T651 has a relationship with the $\mathrm{Cu}$-rich intergranular phase, which increases local corrosion susceptibility. In testing 
using river water testing media, no significant changes were seen on the surface of the propeller. Although pitting occurs quite clearly on propellers with Al 7075 T651 material, it is not followed by peeling as happened in seawater testing.

\section{Conclusion}

From the results of this study, several conclusions are drawn as follows:

1. The higher the rotational speed of the propeller, the greater the weight reduction of the propeller.

2. The smaller the surface roughness value, the greater the weight loss due to fluid friction and silica sand on the surface of the propeller.

3. The propeller with seawater testing media with $1000 \mathrm{rpm}$ rotation experiences the most severe erosion-corrosion.

\section{References}

[1] S. Siproni, M. Rasid, D. Seprianto, dan Y. Yahya, "Effect of Casting Process on Mechanical Properties of Motor Boat Propellers," Austenit, vol. 10, no. 1, 2018. [in Bahasa].

[2] Z. Wu, Y. F. Cheng, L. Liu, W. Lv, dan W. Hu, "Effect of heat treatment on microstructure evolution and erosion-corrosion behavior of a nickel-aluminum bronze alloy in chloride solution," Corrosion Science, vol. 98, pp. 260-270, 2015.
[3] A. Naimi, H. Yousfi, dan M. Trari, "Microstructure and corrosion resistance of molybdenum and aluminum coatings thermally sprayed on 7075-T6 aluminum alloy," Protection of Metals and Physical Chemistry of Surfaces, vol. 48, no. 5, pp. 557-562, 2012.

[4] Y. Liu, J. Mol, dan G. Janssen, "Combined corrosion and wear of aluminum alloy 7075-T6," Journal of Bio-and Tribo-Corrosion, vol. 2, no. 2, pp. 9, 2016.

[5] A. D. Isadare, B. Aremo, M. O. Adeoye, O. J. Olawale, dan M. D. Shittu, "Effect of heat treatment on some mechanical properties of 7075 aluminum alloy," Materials Research, vol. 16, no. 1, pp. 190-194, 2013.

[6] M. G. Fontana, Corrosion engineering. Tata McGraw-Hill Education, 2005.

[7] K. R. Trethewey dan J. Chamberlain, "corrosion for students and Engineering," Jakarta: Gramedia, 1991. [in Bahasa].

[8] D. H. Sutjahjo dan others, "Time and Salinity of Sea Water Against Corrosion Rate of Bronze Metal (Bronze) As Ship Propeller," Jurnal Teknik Mesin, vol. 5, no. 02, 2017. [in Bahasa]

[9] J. R. Davis, "Aluminum and aluminum alloys," 2013.

[10] S. Huda dan A. Aristianto, "Effect of Artificial Aging on Corrosion Rate of Aluminum Motor Boat Propellers," Teknologi, vol. 4, 2011. [in Bahasa]

[11]E. J. Sasono, E. Canepa, R. Stifanese, L. Merotto, dan P. Traverso, "Corrosion behavior of aluminum alloys in deep-sea environment: A review and the KM3NeT test results," Marine Structures, vol. 59, no. 2, pp. 271-284, 20092018.

[12]E. Canepa, R. Stifanese, L. Merotto, dan P. Traverso, "Corrosion behavior of aluminum alloys in deep-sea environment: A review and the KM3NeT test results," Marine Structures, vol. 59, pp. 271-284, 2018. 